\title{
Identification of circulating tumor DNA using a targeted 545-gene next generation sequencing panel in patients with gastric cancer
}

\author{
JING LAN $^{1}$, YAPING LU ${ }^{2}$, YANFANG GUAN ${ }^{2}$, LIANPENG CHANG $^{2}$, ZHENGYUAN YU $^{3}$ and HAIXIN QIAN ${ }^{1}$ \\ ${ }^{1}$ Department of General Surgery, The First Affiliated Hospital of Soochow University, Suzhou, Jiangsu 215006; \\ ${ }^{2}$ Research and Development Department, Geneplus-Beijing Institute, Beijing 102206; ${ }^{3}$ Department of Oncology, \\ The First Affiliated Hospital of Soochow University, Suzhou, Jiangsu 215006, P.R. China
}

Received August 24, 2018; Accepted June 5, 2019

DOI: $10.3892 / \mathrm{ol} .2020 .11305$

\begin{abstract}
Gastric cancer (GC) is characterized by unique genetic aberrations. Some of these mutations may be used to predict tumor prognosis or to guide patient therapy. Cell-free circulating tumor DNA (ctDNA) has been considered a promising alternative to biopsy to identify genome aberrations. However, no standardized methods to detect ctDNA variations in patients with GC are currently available. In the present study, the targeted sequencing of 545 genes was used to identify somatic alterations in tissues and matched plasma samples of nine patients with GC. Driver gene mutations were detected in matched tissues and plasma ctDNA. The mutated reads concordance rate of ctDNA in GC tissues with matched tissues was $45 \%$. A true positive copy number gain of human epidermal growth factor receptor 2 in plasma from patients with GC was identified. Furthermore, the ctDNA fraction in plasma cell-free DNA (cfDNA) was positively correlated with metastasis lymph node number and with lactate dehydrogenase level. In conclusion, results from the present study suggested that targeted sequencing of plasma ctDNA may be considered a potential option for the clinical monitoring of GC.
\end{abstract}

\section{Introduction}

Gastric cancer (GC) is a highly heterogeneous malignant disease characterized by a unique pattern of genome driver aberrations. Some of these aberrations are used to predict

Correspondence to: Dr Zhengyuan Yu, Department of Oncology, The First Affiliated Hospital of Soochow University, 899 Pinghai Road, Suzhou, Jiangsu 215006, P.R. China

E-mail: strongeryy1985@163.com

Professor Haixin Qian, Department of General Surgery, The First Affiliated Hospital of Soochow University, 899 Pinghai Road, Suzhou, Jiangsu 215006, P.R. China

E-mail: qianhaixinjiangsu@163.com

Keywords: gastric cancer, noninvasive,ctDNA, targeted sequencing, HER2 development of the disease or guide therapy (1-3). For example, overexpression of human epidermal growth factor receptor 2 (HER2) is detected in GC and can be considered a novel therapeutic agent (4-6). However, the genome aberration profile can change throughout the course of therapy, and many patients with GC develop acquired drug resistance along with tumor evolution $(7,8)$. Detecting variations prior to and during therapy is therefore crucial to improve patient outcome. However, repeated invasive tissue biopsies of GC are not feasible due to the clinical risk of tumor spread. Cell-free circulating tumor DNA (ctDNA) has attracted increasing attention and may be considered a potential tumor marker. In addition, its detection is convenient and non invasive (9). Analysis of ctDNA presents therefore a potentially clinical prospect in the treatment and auxiliary diagnosis of GC.

Numerous approaches, including the BEAMing (beads, emulsion, amplification, and magnetics) method, the Scorpion ARMS method that detects epidermal growth factor receptor aberration and the droplet digital polymerase chain reaction method that detect HER2 amplification, have been successfully used to identify ctDNA aberrations in patients with various types of cancer (10-15). Furthermore, a previous study using next generation sequencing (NGS) to detect ctDNA in the bloodstream of patients with GC has identified concordant variations between ctDNA and tumor DNA (tDNA); however, this study only primarily focused on a small cohort of genes, including tumor protein p53 (TP53) (16). However, due to the high heterogeneity of GC, numerous genes may be involved and available for analysis. To explore the association between ctDNA and the clinical characteristics of patients with GC, the present study used a targeted capture sequencing method to detect variations at known hot-spot loci of 545 cancer-associated genes in tumor and plasmatic ctDNA from nine patients with GC.

\section{Materials and methods}

Patients and samples. The present study was approved by the Ethics Committees of the First Affiliated Hospital of Soochow University. All patients provided written informed consent for the use of their blood and tumor samples. Nine patients diagnosed with advanced GC and received surgery or palliative surgery were involved in this study. Tumor staging was 
performed according to the 7th American Joint Committee on Cancer (AJCC) TNM system (17). All samples and medical data used in this study have been irreversibly anonymized. Gastric tumor and plasma samples from nine patients with GC were analyzed (Table I). All 9 patients, including six men and three women, were diagnosed with adenocarcinoma. Smoking history was not assessed. Tumor tissues obtained from biopsies taken at diagnosis or during surgery were fixed in formalin at room temperature for 6-48 $\mathrm{h}$, then embedded in paraffin as previously described (18). HER2 Immunohistochemistry (IHC) was carried out on formalin-fixed, $5-\mu \mathrm{m}$ thick, paraffin-embedded (FFPE) tissue sections (Ventana; Roche) using a pre-diluted antibody (ready to use) of monoclonal rabbit PATHWAY anti-HER2 (4B5; Bench Mark GX; Roche Diagnostics K.K.). Briefly, the FFPE sections were deparaffinized. After cell conditioning, it was incubated with primary monoclonal rabbit PATHWAY anti-HER 2 at $37^{\circ} \mathrm{C}$ for $30 \mathrm{~min}$. Counterstaining was performed by incubation with hematoxylin at room temperature for $8 \mathrm{~min}$, followed by incubation with building reagent for $12 \mathrm{~min}$. Staining was scored as follows: 0 , no membrane staining or no reactivity; +1 , cancer cell cluster with a barely/faint perceptible membranous reactivity; +2 , tumor cell cluster with a weak to moderate complete, basolateral, or lateral membranous reactivity; +3 , tumor cell cluster with a strong complete, basolateral, or lateral membranous reactivity. Tissues with a score of +3 , or +2 in addition to fluorescence in situ hybridization (FISH) positivity, were considered as HER2 positive. Peripheral blood samples were collected from patients one week prior to surgery.

Sample processing and DNA extraction. Two types of samples were collected from each patient, tumor tissue (fresh and FFPE) and $20 \mathrm{ml}$ peripheral blood (PB) prior to surgery. DNA was extracted from fresh tissue using E.Z.N.A. Tissue DNA kit (Omega Bio-Tek), and from FFPE tissue using QIAamp DNA FFPE Tissue kit (Qiagen) according to the manufacturer's instructions. EDTA tubes containing blood samples were centrifuged for $10 \mathrm{~min}$ at $1,000 \mathrm{x}$ g at $4^{\circ} \mathrm{C}$. Cell layer containing peripheral blood lymphocytes (PBLs) was collected and transferred into 1-ml Eppendorf tubes and stored at $-20^{\circ} \mathrm{C}$ until further use. Supernatants were further centrifuged at $10,000 \times \mathrm{g}$ at $4^{\circ} \mathrm{C}$ for $10 \mathrm{~min}$ and plasma was collected and stored at $-80^{\circ} \mathrm{C}$ until further use. DNA from PBLs was extracted using the E.Z.N.A. Blood DNA kit (Omega Bio-Tek), whereas ctDNA was extracted from at least $1 \mathrm{ml}$ plasma using QIAamp Circulating Nucleic Acid kit (Qiagen) following the manufacturer's instructions. DNA was quantified with the Qubit 2.0 Fluorometer and the Qubit dsDNA HS Assay kit (Life Technologies; Thermo Fisher Scientific, Inc.) according to the recommended protocols.

Sequencing library construction and target enrichment. DNA $(1 \mu \mathrm{g})$ from tissue and PBLs was cropped into 300-bp fragments with a Covaris S2 ultrasonicator as previously described (19). Libraries of DNA from tissue, PBLs germline and circulating DNA were prepared with the KAPA Library Preparation kit (Kapa Biosystems) according to the manufacturer's protocol. A custom SeqCap EZ Library (Roche NimbleGen, Inc.) was designed for targeted capture. To explore the comprehensive genetic properties of GC, the capture probe was designed
Table I. Clinicopathological characteristics of the nine patients with gastric cancer.

\begin{tabular}{lc} 
Characteristics & Number (\%) \\
\hline Age (years) & \\
Mean (SD) & $62.89(9.27)$ \\
Median (range) & $64(46-77)$ \\
Sex & \\
Male & $3(33.33 \%)$ \\
Female & $6(66.67 \%)$ \\
Pathological diagnosis & \\
Gastric adenocarcinoma & $9(100 \%)$ \\
Tumor stage & \\
II & $3(33.33 \%)$ \\
III & $5(55.56 \%)$ \\
IV & $1(11.11 \%)$
\end{tabular}

$\mathrm{SD}$, standard deviation.

according to genomic regions (total approximately $1.7 \mathrm{Mb}$ in size, data not shown) of the 545 genes most frequently mutated in gastric tumor and other common solid tumors. Capture hybridization was carried out according to the manufacturer's protocol.

$N G S$ sequencing. Sequencing was carried out using Illumina 2x100 bp paired-end reads on an Illumina HiSeq 3000 instrument according to the manufacturer's recommendations and using TruSeq PE Cluster Generation Kit v3 and the TruSeq SBS Kit v3 (Illumina, Inc.).

Analysis of sequencing data. After removal of terminal adaptor sequences and low-quality data, reads were mapped to the reference human genome and aligned as previously described (19). The Genome Analysis Toolkit (https://www. broadinstitute.org/gatk/) and MuTect (20) were used to call somatic small insertions and deletions and single nucleotide variants by filtering PBL germline mutations. The following somatic mutations obtained were further filtered as follows: i) All mutations from tissues and plasma should present $\geq 5$ and $\geq 2$ mutated reads, respectively; ii) the frequency of mutations in tissue should be $\geq 3 \%$; and iii) mutated reads of each mutations should be observed on both strands. Copy number variations (CNV) were generated using Copy Number Targeted Resequencing Analysis (http://contra-cnv.sourceforge.net; version 2.0.3) (21). BreakDancer algorithm was used to detect tumor-associated structure variations (22). The final candidate variants were manually verified with the Integrative Genomics Viewer (IGV) browser (https://software.broadinstitute.org/software/igv) (23). COSMIC database (https://cancer. sanger.ac.uk/cosmic) was used to determine the occurrence of variants.

Statistical analysis. Pearson's correlation and one-way ANOVA followed by Bonferroni correction post-hoc test were performed using SPSS software (version 16.0; SPSS, Inc.) to 


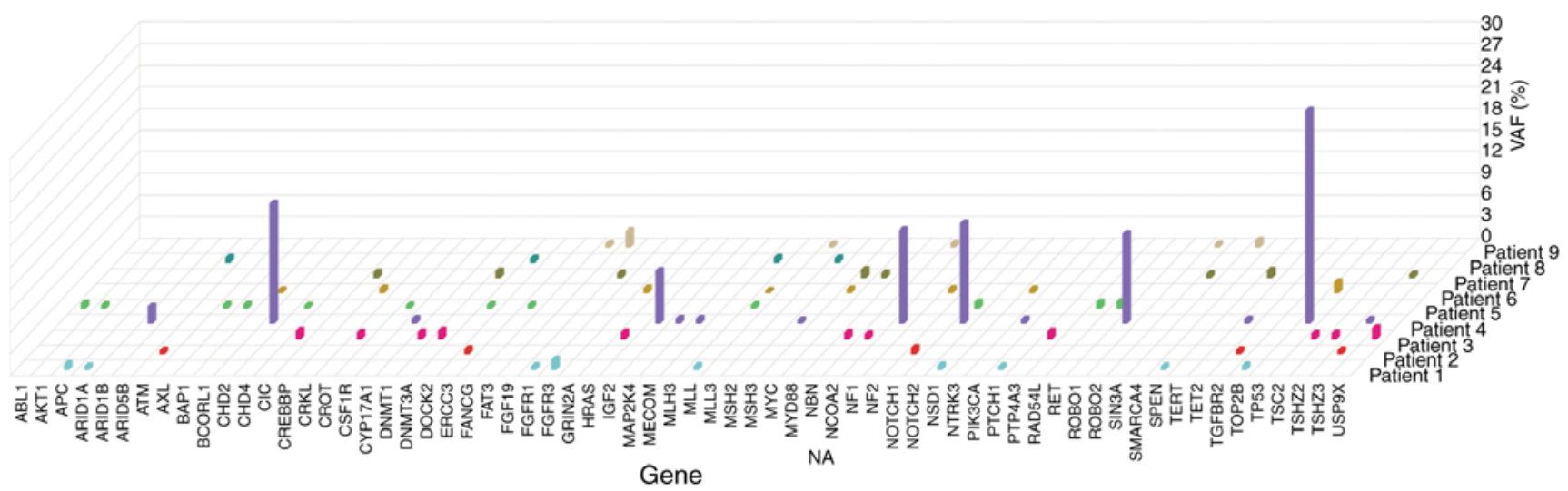

B Somatic mutations in tissue samples of gastric cancer patients

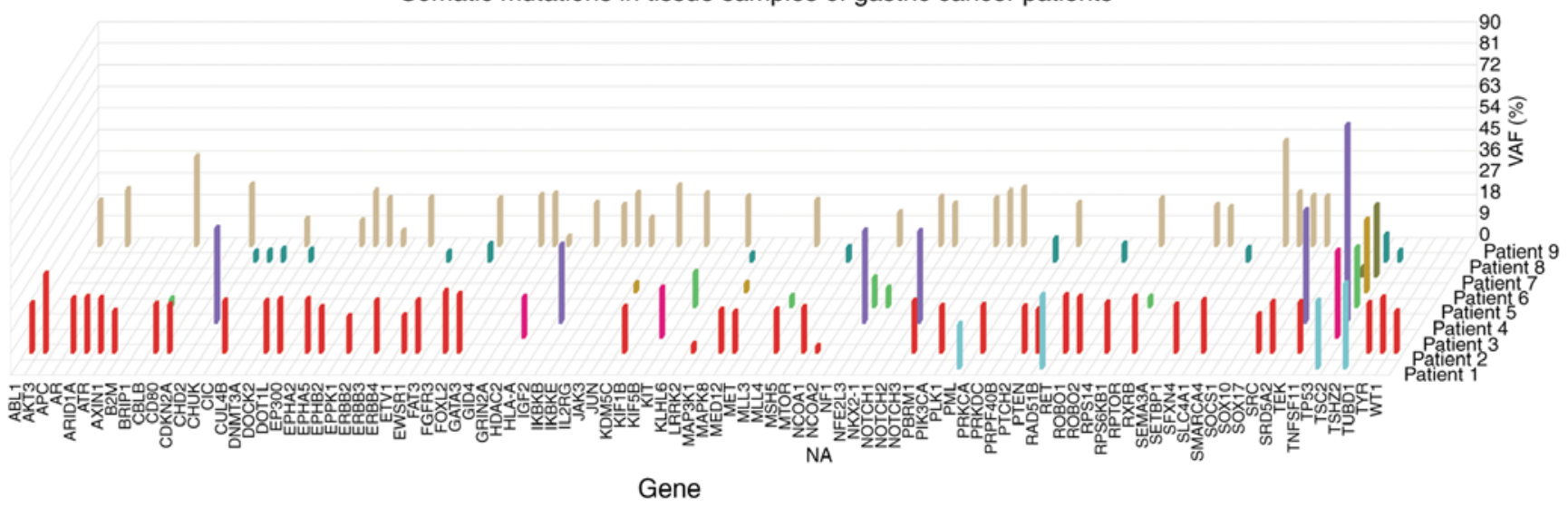

Figure 1. Somatic mutations in (A) tissues and (B) plasma samples from nine patients with gastric cancer. VAF, variated allele frequency.

analyze the correlation between ctDNA fraction and clinical characteristics, including metastasis lymph node number and lactate dehydrogenase (LDH) content, as previously described (24). $\mathrm{P}<0.05$ was considered to indicate a statistically significant difference.

\section{Results}

Sequencing coverage of the target region. Of all nine paired samples, capture sequencing data demonstrated a mean coverage of $904 \mathrm{x}$ in tissues (ranging from $275 \mathrm{x}$ to $1,255 \mathrm{x}$; data not shown) and of $1,375 \mathrm{x}$ in plasmas (ranging from $965 \mathrm{x}$ to $2,203 x$; data not shown). Furthermore, approximately $99 \%$ of the target region was covered at $>20 x$. For each sample type, the gene coverage was uniformly distributed, with $>167 \mathrm{x}$ in $92.73 \%$ of tissue genes and $>500 x$ in $87.71 \%$ of plasma genes (data not shown). In this case, mutations of most genes in both sample types could possess at least 5 support reads at a frequency of approximately $1 \%$ in plasma or approximately $3 \%$ in tissue.

Somatic mutations in tissue and plasma samples. Somatic mutations were detected in all tissues and matched plasma samples (100\%). The number of non-synonymous somatic mutations detected in tissues ranged from 2 to 46, with a mean value of 16 . The mean variant allele fraction (VAF) was $18.85 \%$. In plasma, a total of 80 non-synonymous somatic mutations were detected, with a mean VAF of $1.90 \%$. Among all mutations, 32 mutations in tissues and 17 mutations in plasma were confirmed in COSMIC database.

Mutation spectrums of the 9 GC tissues revealed great inter-individual tumor genetic heterogeneity (Fig. 1). Notably, seven patients $(78 \%)$ presented TP53 gene mutations, which occurred at six different amino acid positions (p.T211Nfs*5, p.C176F, p.P190L, p.R213*, p.E271V and p.G245S). However, the structure variations were not detected in tissues and plasma samples.

Mutation concordance between tissue and plasma. In all detected non-synonymous somatic mutations, capture sequencing identified a total of eight concordant mutations in both tissue and plasma samples in four of the nine patients with GC (44\%). Notably, in patient 4, who was the only patient diagnosed with distant metastasis, five out of six tumor-derived mutations were found in plasma ctDNA. In addition, the results from further analysis of plasma samples sequencing data demonstrated that $45 \%$ of mutation in tissue presented concordant mutation in the plasma ctDNA of all patients (Fig. 2).

CNV amplification of HER2 in FFPE and plasma samples. Prior to sequencing, immunohistochemistry (IHC) was performed on GC FFPE to assess HER2 expression. The results demonstrated that only two patients (22.22\%) expressed HER2 (Fig. 3). Based on capture sequencing, CNV of HER2 

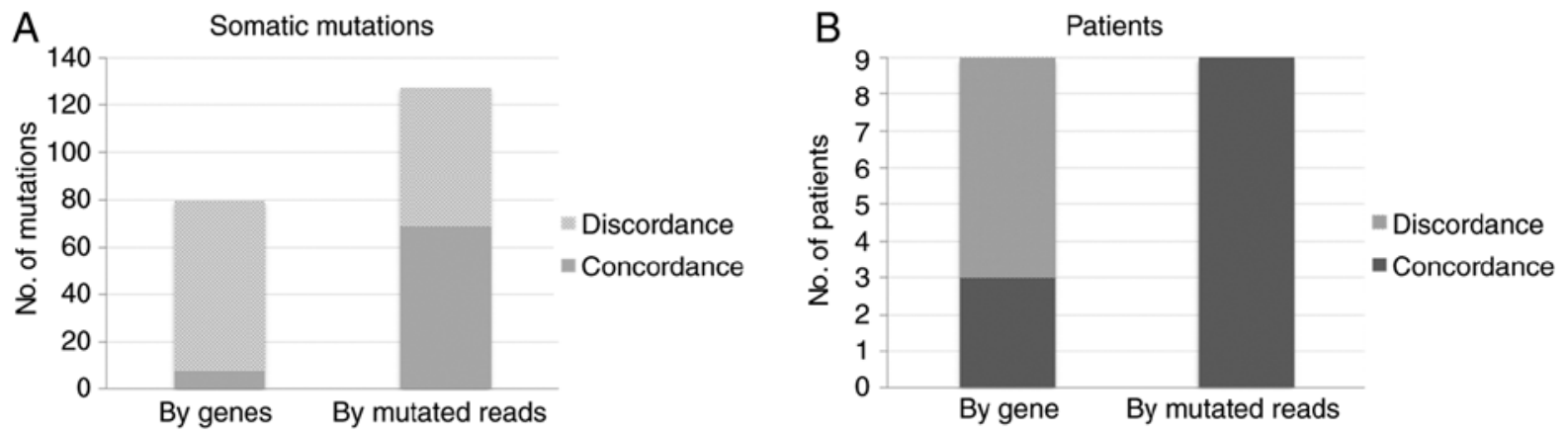

Figure 2. Concordant mutated (A) gene and (B) patients calculated by genes or mutated reads. No, number.
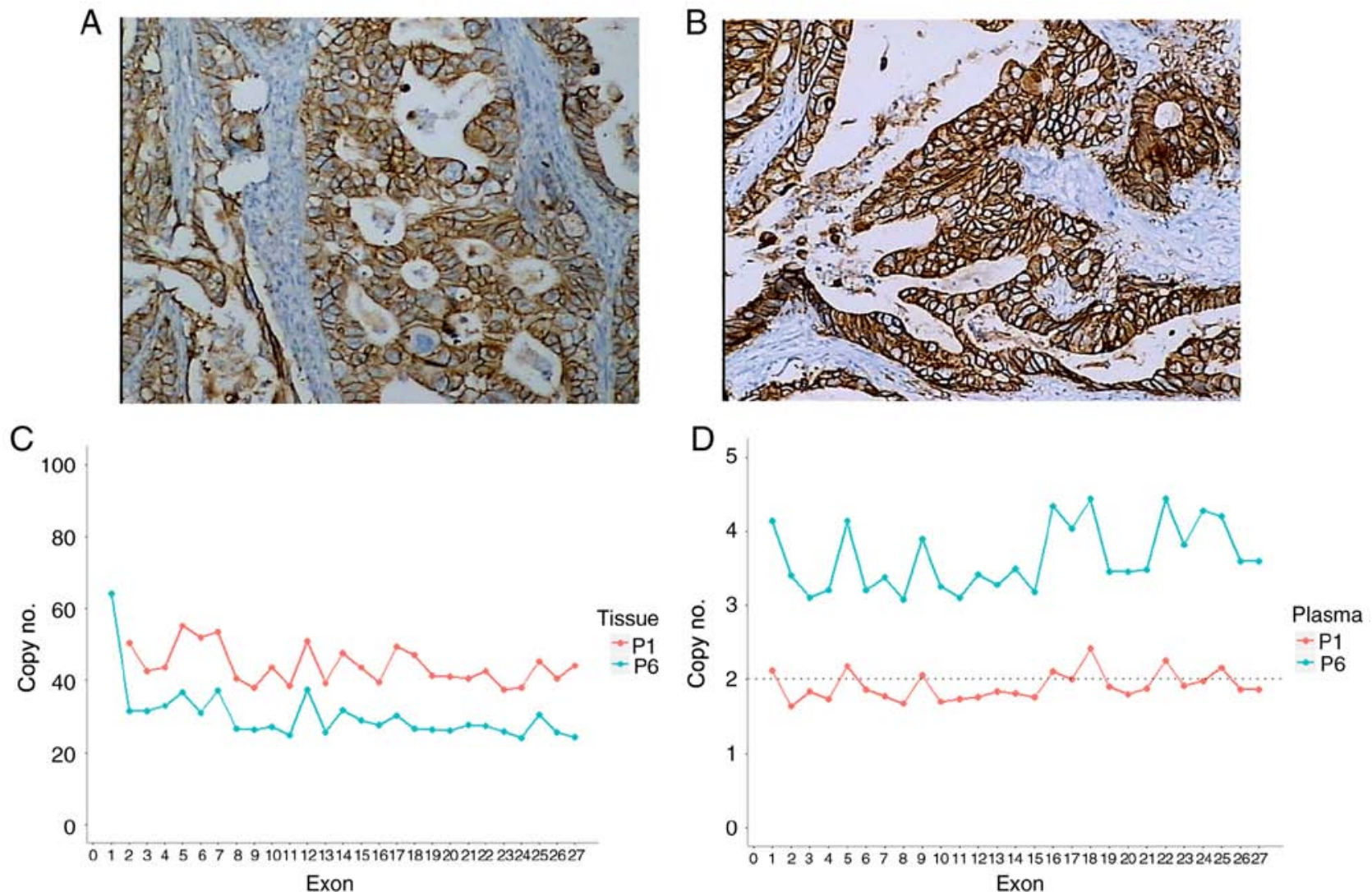

Figure 3. (A and B) Copy number variations of epidermal growth factor receptor 2 detected by immunohistochemistry and (C and D) capture sequencing. No, number; P1, patient 1; P6, patient 6.

was analyzed in tissue and matched plasma by comparing reads depth with PBL. Significant copy number gains of $H E R 2$ in tissue samples was detected in these two patients (22.22\%) [patient no. 1 (P1), copy no. $=46.2, \mathrm{P}<0.01$; patient no. 6 (P6), copy no. $=30.3, \mathrm{P}<0.01]$. Other $\mathrm{CNV}$ negative results were in accordance with IHC assess (25). Furthermore, only P6 presented a significant HER2 gene amplification in plasma ctDNA $(\mathrm{P}<0.01)$, and the fold-change of copy no. was only 3.6. In addition, analysis of plasma ctDNA from P1 demonstrated relative depth of all HER2 exons that fluctuated around 2.

Correlation between ctDNA fraction and clinical characteristics of patients with GC. The correlation between ctDNA fraction and clinical characteristics of patients with $\mathrm{GC}$ was analyzed. Based on the number of metastasis lymph nodes, patients were divided into two groups, a low metastasis lymph node (LMLN) group including N1 and N2 patients and a high metastasis lymph node (HMLN) group including N3 patients. The mean of ctDNA fraction in HMLN group was significantly higher than in LMLN group ( $\mathrm{P}=0.03$; Fig. 4). In addition, the ctDNA fraction and the LDH level were positively correlated in all groups ( $\mathrm{r}=0.85 ; \mathrm{P}=0.003$; Fig. 5 ).

\section{Discussion}

Targeted capture sequencing is an economical and effective method used to explore the genomic characteristic (26-28). By using capture sequencing of 545 genes at a mean depth of $904 \mathrm{x}$ in tissues and $1375 \mathrm{x}$ in plasma, the present study reported numerous inter-individual molecular differences among 


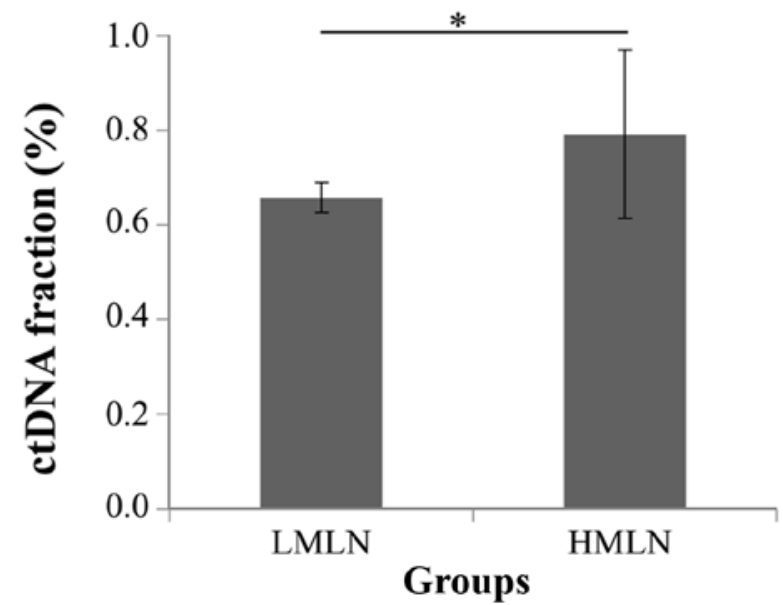

Figure 4. The mean of ctDNA fraction in LMLN group and HMLN groups. Values are expressed as the means \pm standard deviation of four separate experiments. ${ }^{*} \mathrm{P}<0.05$. ctDNA, cell-free circulating tumor DNA; HMLN, high metastasis lymph node; LMLM, low metastasis lymph node.

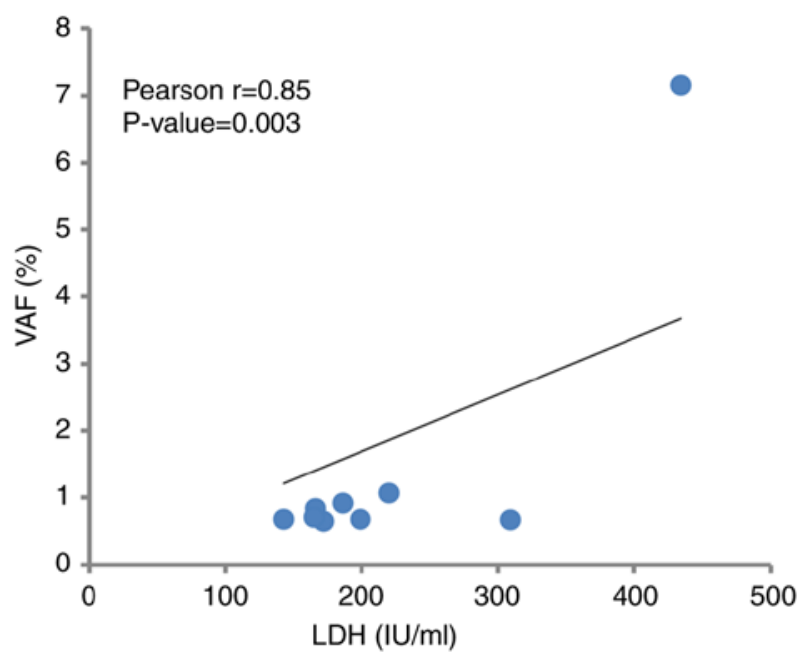

Figure 5. Pearson's correlation analysis between ctDNA fraction and LDH level. ctDNA, cell-free circulating tumor DNA; IU, international unit; LDH, lactate deshydrogenase.

patients with GC. Mutations frequently occurred on TP53 gene and occurred at six different amino acid positions, which suggested that this PCR-based method could only be applied in a limited number of patients with hot-spot mutations. However, capture sequencing, whole exome sequencing or whole genome sequencing may be more suitable to identify cancer mutations, and would decrease the cost of sequencing (29).

The present study detected the mutation in plasma samples of patients with GC in a non-invasive way. The results demonstrate that $45 \%$ mutations in paired GC tissues presented concordant mutated reads in plasma samples from all 9 patients. Furthermore, additional de novo mutations in the DNA in the plasma can be induced by spatial heterogeneity of the lesion (30). A previous study reported that, in a case of metastatic breast cancer, multiregional tumor biopsies vary from each other, and that ctDNA present the mutations of both primary tumor and metastases (31). Similarly, a study revealed that ctDNA contains variations from heterogeneous regions in the primary lung cancer lesion (32). Notably, in the only stage IV patient (P6) with distant metastasis from the present study, the consistency of mutations in plasma and tissue was of $83 \%$, which may be due to the high ctDNA level of patients with distant metastasis (33). This result indicated that the non-invasive ctDNA detection may offer more benefit in late-stage patients.

One crucial purpose of molecular diagnosis in patients with cancer is to determine sensitive drug targets (34), including HER2, which could be specifically bound by herceptin, which is a monoclonal antibody used in anticancer therapy (35). The present study identified two true-positive $H E R 2 \mathrm{CNV}$ in patients. Regarding plasma samples, despite the high dilution of cfDNA, the true positive HER2 gain was detected in one case, which suggested that non-invasive ctDNA analysis in CNV is a viable method to determine target drugs for patients with GC. However, it is crucial to improve the sensitivity of ctDNA CNV detection.

The correlation between ctDNA fraction and clinical characteristics from patients with GC was determined. The results demonstrated that ctDNA fraction was abundant in patients with more metastasis lymph nodes. This result suggested that metastasis ability of tumor may be associated with ctDNA fraction in plasma. In addition, this result further explained the high ctDNA level observed in one case of stage IV GC (P6), which caused the high consistency of mutations between ctDNA and tDNA. Future studies should involve the detection of more clinical serum biomarker, including carcinoembryonic antigen, CA19-9 and HER2 expression level (36,37). Detection of ctDNA as a biomarker has been considered a sensitive and specific method in the prognosis and monitoring of breast and colorectal cancers $(38,39)$. However, ctDNA were not monitored for disease progression or remission, following surgery, and were not investigated following chemotherapy. This was an inevitable limitation of the present study. Since such investigation has not been made in GC, future study will involve ctDNA monitoring following treatment in GC. The results from the present study need to be further confirmed in a larger patient population. This could provide important findings on the use of ctDNA in GC. As a promising tool, the noninvasive detection of ctDNA may represent a promising tool in the individual treatment and monitoring of patients with GC.

\section{Acknowledgements}

Not applicable.

\section{Funding}

The present study was supported by the National Science Foundation of China (grant no. 81702048) and the Suzhou Science and Technology Bureau project (grant no. SYS201609).

\section{Availability of data and materials}

The datasets used and/or analyzed during the present study are available from the corresponding author upon reasonable request.

\section{Authors' contributions}

ZY and HQ designed the study. JL and ZY collected samples and clinical data. JL, YL, YG and LC peformed the analysis 
and interpretation of the data. JL, YL, YG and LC wrote the manuscript. All authors contributed to the drafting and revision of the manuscript.

\section{Ethics approval and consent to participate}

The present study was approved by the Ethics Committee of the First Affiliated Hospital of Soochow University. All patients provided written informed consent prior to the study start.

\section{Patients consent for publication}

Not applicable.

\section{Competing interests}

The authors declare that they have no competing interests.

\section{References}

1. Roviello G, Ravelli A, Polom K, Petrioli R, Marano L, Marrelli D, Roviello F and Generali D: Apatinib: A novel receptor tyrosine kinase inhibitor for the treatment of gastric cancer. Cancer Lett 372: 187-191, 2016.

2. Cancer Genome Atlas Research Network: Comprehensive molecular characterization of gastric adenocarcinoma. Nature 513: 202-209, 2014

3. Cristescu R, Lee J, Nebozhyn M, Kim KM, Ting JC, Wong SS, Liu J, Yue YG, Wang J, Yu K, et al: Molecular analysis of gastric cancer identifies subtypes associated with distinct clinical outcomes. Nat Med 21: 449-456, 2015.

4. Espelin CW, Leonard SC, Geretti E, Wickham TJ and Hendriks BS: Dual HER2 targeting with trastuzumab and liposomal-encapsulated doxorubicin (MM-302) demonstrates synergistic antitumor activity in breast and gastric cancer. Cancer Res 76: 1517-1527, 2016.

5. Gravalos $\mathrm{C}$ and Jimeno A: HER2 in gastric cancer: A new prognostic factor and a novel therapeutic target. Ann Oncol 19: $1523-1529,2008$.

6. Bang YJ, Van Cutsem E, Feyereislova A, Chung HC, Shen L, Sawaki A, Lordick F, Ohtsu A, Omuro Y, Satoh T, et al: Trastuzumab in combination with chemotherapy versus chemotherapy alone for treatment of HER2-positive advanced gastric or gastro-oesophageal junction cancer (ToGA): A phase 3, open-label, randomised controlled trial. Lancet 376: 687-697, 2010.

7. Chen K, Yang D, Li X, Sun B, Song F, Cao W, Brat DJ, Gao Z, $\mathrm{Li} \mathrm{H}$, Liang $\mathrm{H}$, et al: Mutational landscape of gastric adenocarcinoma in Chinese: Implications for prognosis and therapy. Proc Natl Acad Sci USA 112: 1107-1112, 2015.

8. Park H, Cho SY, Kim H, Na D, Han JY, Chae J, Park C, Park OK, Min S, Kang J, et al: Genomic alterations in BCL2L1 and DLC1 contribute to drug sensitivity in gastric cancer. Proc Natl Acad Sci USA 112: 12492-12497, 2015.

9. Hutchinson L: Biomarkers: ctDNA-identifying cancer before it is clinically detectable. Nat Rev Clin Oncol 12: 372, 2015.

10. Taniguchi K, Uchida J, Nishino K, Kumagai T, Okuyama T, Okami J, Higashiyama M, Kodama K, Imamura F and Kato K: Quantitative detection of EGFR mutations in circulating tumor DNA derived from lung adenocarcinomas. Clin Cancer Res 17: 7808-7815, 2011.

11. Kinugasa H, Nouso K, Tanaka T, Miyahara K, Morimoto $Y$, Dohi C, Matsubara T, Okada H and Yamamoto K: Droplet digital PCR measurement of HER2 in patients with gastric cancer. $\mathrm{Br}$ J Cancer 112: 1652-1655, 2015.

12. Kim HR, Lee SY, Hyun DS, Lee MK, Lee HK, Choi CM, Yang SH, Kim YC, Lee YC, Kim SY, et al: Detection of EGFR mutations in circulating free DNA by PNA-mediated PCR clamping. J Exp Clin Cancer Res 32: 50, 2013.

13. Douillard JY, Ostoros G, Cobo M, Ciuleanu T, Cole R, McWalter G, Walker J, Dearden S, Webster A, Milenkova T and McCormack R: Gefitinib treatment in EGFR mutated caucasian NSCLC: Circulating-free tumor DNA as a surrogate for determination of EGFR status. J Thorac Oncol 9: 1345-1353, 2014.
14. Hamakawa T, Kukita Y, Kurokawa Y, Miyazaki Y, Takahashi T, Yamasaki M, Miyata H, Nakajima K, Taniguchi K, Takiguchi $\mathrm{S}$, et al: Monitoring gastric cancer progression with circulating tumour DNA. Br J Cancer 112: 352-356, 2015.

15. Shoda K, Ichikawa D, Fujita Y, Masuda K, Hiramoto H, Hamada J, Arita T, Konishi H, Komatsu S, Shiozaki A, et al: Monitoring the HER2 copy number status in circulating tumor DNA by droplet digital PCR in patients with gastric cancer. Gastric Cancer 20: 126-135, 2017.

16. Kukita Y, Matoba R, Uchida J, Hamakawa T, Doki Y, Imamura F and Kato K: High-fidelity target sequencing of individual molecules identified using barcode sequences: De novo detection and absolute quantitation of mutations in plasma cell-free DNA from cancer patients. DNA Res 22: 269-277, 2015.

17. Washington $\mathrm{K}: 7$ th Edition of the AJCC cancer staging manual: Stomach. Ann Surg Oncol 17: 3077-3079, 2010.

18. Nagahashi M, Shimada Y, Ichikawa H, Nakagawa S, Sato N, Kaneko K, Homma K, Kawasaki T, Kodama K, Lyle S, et al: Formalin-fixed paraffin-embedded sample conditions for deep next generation sequencing. J Surg Res 220: 125-132, 2017.

19. Yang X, Chu Y, Zhang R, Han Y, Zhang L, Fu Y, Li D, Peng R, Li D, Ding J, et al: Technical validation of a next-generation sequencing assay for detecting clinically relevant levels of breast cancer-related single-nucleotide variants and copy number variants using simulated cell-free DNA. J Mol Diagn 19, 525-536. 2017.

20. Cibulskis K, Lawrence MS, Carter SL, Sivachenko A, Jaffe D, Sougnez C, Gabriel S, Meyerson M, Lander ES and Getz G, et al: Sensitive detection of somatic point mutations in impure and heterogeneous cancer samples. Nat Biotechnol 31: 213-219, 2013.

21. Li J, Lupat R, Amarasinghe KC, Thompson ER, Doyle MA Ryland GL, Tothill RW, Halgamuge SK, Campbell IG and Gorringe KL: CONTRA: Copy number analysis for targeted resequencing. Bioinformatics 28: 1307-1313, 2012.

22. Chen K, Wallis JW, McLellan MD, Larson DE, Kalicki JM, Pohl CS, McGrath SD, Wendl MC, Zhang Q, Locke DP, et al: BreakDancer: An algorithm for high-resolution mapping of genomic structural variation. Nat Methods 6: 677-681, 2009.

23. Robinson JT, Thorvaldsdottir H, Winckler W, Guttman M, Lander ES, Getz G and Mesirov JP: Integrative genomics viewer. Nat Biotechnol 29: 24-26, 2011.

24. Yuan ZY, Gao SG, Mu JW, Xue Q, Mao YS, Wang DL, Zhao J, Gao YS, Huang JF and He J: Prognostic value of preoperative serum lactate dehydrogenase in thymic carcinoma. J Thoracic Dis 8: 2464-2472, 2016.

25. Wang Y, Zhao C, Chang L, Jia R, Liu R, Zhang Y, Gao X, Li J, Chen R, Xia X, Bulbul A, et al: Circulating tumor DNA analyses predict progressive disease and indicate trastuzumab-resistant mechanism in advanced gastric cancer. EBioMedicine 43: 261-269, 2019.

26. Yu J, Wu WK, Li X, He J, Li XX, Ng SS, Yu C, Gao Z, Yang J, $\mathrm{Li} \mathrm{M}$, et al: Novel recurrently mutated genes and a prognostic mutation signature in colorectal cancer. Gut 64: 636-645, 2015.

27. Voss MH, Hakimi AA, Pham CG, Brannon AR, Chen YB, Cunha LF, Akin O, Liu H, Takeda S, Scott SN, et al: Tumor genetic analyses of patients with metastatic renal cell carcinoma and extended benefit from mTOR inhibitor therapy. Clin Cancer Res 20: 1955-1964, 2014.

28. Drilon A, Wang L, Arcila ME, Balasubramanian S, Greenbowe JR, Ross JS, Stephens P, Lipson D, Miller VA, Kris MG, et al: Broad, Hybrid Capture-based next-generation sequencing identifies actionable genomic alterations in lung adenocarcinomas otherwise negative for such alterations by other genomic testing approaches. Clin Cancer Res 21: 3631-3639, 2015.

29. Murtaza M,Dawson SJ,Pogrebniak K, Rueda OM,Provenzano E, Grant J, Chin SF, Tsui DWY, Marass F, Gale D, et al: Multifocal clonal evolution characterized using circulating tumour DNA in a case of metastatic breast cancer. Nat Commun 6: 8760, 2015.

30. Jacoby MA, Duncavage EJ and Walter MJ: Implications of tumor clonal heterogeneity in the era of next-generation sequencing. Trends Cancer 1: 231-241, 2015.

31. Abbosh C, Birkbak NJ, Wilson GA, Jamal-Hanjani M, Constantin T, Salari R, Le Quesne J, Moore DA, Veeriah S, Rosenthal R, et al: Phylogenetic ctDNA analysis depicts early-stage lung cancer evolution. Nature 545: 446-451, 2017. 
32. Wan JCM, Massie C, Garcia-Corbacho J, Mouliere F, Brenton JD, Caldas C, Pacey S, Baird R and Rosenfeld N: Liquid biopsies come of age: Towards implementation of circulating tumour DNA. Nat Rev Cancer 17: 223-238, 2017.

33. Phallen J, Sausen M, Adleff V, Leal A, Hruban C, White J, Anagnostou V, Fiksel J, Cristiano S, Papp E, et al: Direct detection of early-stage cancers using circulating tumor DNA. Sci Transl Med 9: pii: eaan2415, 2017.

34. Zehir A, Benayed R, Shah RH, Syed A, Middha S, Kim HR, Srinivasan P, Gao J, Chakravarty D, Devlin SM, et al: Mutational landscape of metastatic cancer revealed from prospective clinical sequencing of 10,000 patients. Nat Med 23: 703-713, 2017.

35. Müller V, Clemens M, Jassem J, Al-Sakaff N, Auclair P, Nüesch E, Holloway D, Shing M and Bang YJ: Long-term trastuzumab $\left(\right.$ Herceptin ${ }^{\circledR}$ ) treatment in a continuation study of patients with HER2-positive breast cancer or HER2-positive gastric cancer. BMC Cancer 18: 295, 2018.

36. Oyama K, Fushida S, Tsukada T, Kinoshita J, Watanabe T, Shoji M, Nakanuma S, Okamoto K, Sakai S, Makino I, et al: Evaluation of serum HER2-ECD levels in patients with gastric cancer. J Gastroenterol 50: 41-45, 2015.
37. Shi HZ, Wang YN, Huang XH, Zhang KC, Xi HQ, Cui JX, Liu GX, Liang WT, Wei B and Chen L: Serum HER2 as a predictive biomarker for tissue HER2 status and prognosis in patients with gastric cancer. World J Gastroenterol 23: 1836-1842, 2017.30.

38. Dawson SJ, Tsui DW, Murtaza M, Biggs H, Rueda OM, Chin SF, Dunning MJ, Gale D, Forshew T, Mahler-Araujo B, et al: Analysis of circulating tumor DNA to monitor metastatic breast cancer. N Engl J Med 368: 1199-1209, 2013

39. Tie J, Wang Y, Tomasetti C, Li L, Springer S, Kinde I, Silliman N, Tacey M, Wong HL, Christie M, et al: Circulating tumor DNA analysis detects minimal residual disease and predicts recurrence in patients with stage II colon cancer. Sci Transl Med 8: 346ra392, 2016.

This work is licensed under a Creative Commons Attribution-NonCommercial-NoDerivatives 4.0 International (CC BY-NC-ND 4.0) License. 